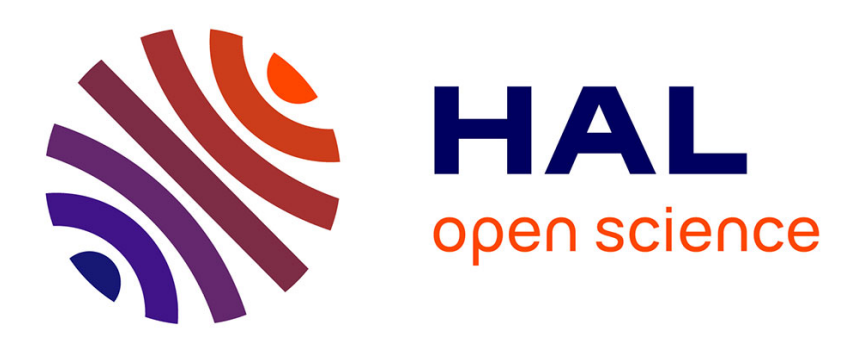

\title{
Stochastic Geometrical and Microstructural Modeling for Solid Oxide Cell Electrodes
}

Hamza Moussaoui, Jérôme Laurencin, Maxime Hubert, Rakesh Sharma, Peter Cloetens, Gérard Delette, Yann Gavet, Johan Debayle

\section{- To cite this version:}

Hamza Moussaoui, Jérôme Laurencin, Maxime Hubert, Rakesh Sharma, Peter Cloetens, et al.. Stochastic Geometrical and Microstructural Modeling for Solid Oxide Cell Electrodes. 16th International Symposium on Solid Oxide Fuel Cells (SOFC-XVI), Sep 2019, Kyoto, Japan. pp.2031 à 2043, 10.1149/09101.2031ecst . hal-02279503

\section{HAL Id: hal-02279503 \\ https://hal.science/hal-02279503}

Submitted on 21 Oct 2019

HAL is a multi-disciplinary open access archive for the deposit and dissemination of scientific research documents, whether they are published or not. The documents may come from teaching and research institutions in France or abroad, or from public or private research centers.
L'archive ouverte pluridisciplinaire HAL, est destinée au dépôt et à la diffusion de documents scientifiques de niveau recherche, publiés ou non, émanant des établissements d'enseignement et de recherche français ou étrangers, des laboratoires publics ou privés. 


\title{
Stochastic Geometrical and Microstructural Modeling for Solid Oxide Cell Electrodes
}

\author{
H. Moussaouia ${ }^{\mathrm{a}}$ J. Laurencin ${ }^{\mathrm{a}}$, M. Hubert ${ }^{\mathrm{b}}$, R. Sharma ${ }^{\mathrm{a}}$, P. Cloetens ${ }^{\mathrm{b}}$, G. Delette ${ }^{\mathrm{a}}$, \\ Y. Gavet ${ }^{\mathrm{c}}$ and J. Debayle ${ }^{\mathrm{c}}$ \\ a Univ. Grenoble Alpes - CEA/LITEN, 38054, Grenoble, France \\ ${ }^{\mathrm{b}}$ European Synchrotron Radiation Facility (ESRF), 38000, Grenoble, France \\ ${ }^{\mathrm{c}}$ Ecole Nationale Supérieure des Mines de Saint-Etienne, SPIN, CNRS 5307, LGF, F- \\ 42023 Saint-Etienne, France
}

\begin{abstract}
As it plays a key role on the performances and durability of solid oxide cells, the electrode microstructure has to be finely characterized and modelled. In this frame, a plurigaussian random field model and an original sphere packing algorithm have been developed to simulate a large variety of electrode microstructures. The two stochastic geometrical models have been validated on various electrode reconstructions obtained by synchrotron X-ray holotomography including the microstructures of thin functional layers and a thick current collector. Afterwards, semi-analytical microstructural correlations have been proposed and validated on a large dataset of representative synthetic microstructures. These equations allow establishing the links between the microstructural properties controlling the performances (Triple Phase Boundary lengths density and specific surface areas) to the 'basic' geometric attributes of the electrode (composition, porosity and particle size distribution). These correlations have been used to model the loss of active TPB1 due to the Ni agglomeration.
\end{abstract}

\section{Introduction}

The electrode microstructure plays a key role on the performances and the durability of Solid Oxide Cells (SOCs) $(1,2)$. In that view, it is essential to unravel the complex relationships linking the main microstructural properties controlling the electrode response to the 'basic' geometric attributes of the electrode microstructure (i.e. composition, porosity and Particle Size Distribution (PSD)). In order to establish these correlations, a first strategy consists in the manufacturing of different electrode microstructures by changing the composition, the porosity and the PSD of the initial powder. The microstructural properties can be estimated with the acquisition of 3D electrode reconstructions obtained by X-ray Computed Tomography (XCT) or by Focused Ion Beam Scanning Electron Microscopy (FIB-SEM) $(3,4)$. This experimental approach requires a large number of samples for the parametric studies. However, the number of experiments is generally very limited as the method is very time consuming. To overcome this issue, an alternative approach is based on the generation of synthetic microstructures that can be obtained either by the random packing of initial particles $(5,6)$ or by geostatistical simulations (7). In this case, emulating representative digital twins of the real electrodes is of central importance to avoid any shortcomings. 
In this work, a plurigaussian random field model based on geostatistical simulations (8) and an original sphere packing algorithm have been proposed (9). Both methods aim at simulating microstructures of typical SOCs electrode manufactured by powder sintering (e.g. screen printing, tape casting). The fundamental difference between the two models allows providing two approximations of a same microstructure, and hence, drawing conclusions that are independent of the chosen model. Besides, using two models enables sweeping a larger range of microstructures and thus evaluating various promising electrode architectures. For both methods, a specific attention has been paid to build the models in such a way that they are able to mimic accurately the electrode microstructures. To check this assertion, they have been validated on different electrode reconstructions. Afterwards, semi-analytical microstructural correlations for the density of Triple Phase Boundary length (TPBl) and the interfacial specific surface areas have been validated on a large dataset of representative synthetic microstructures (10). These correlations are used to model the loss of active TPBl due to the Ni agglomeration.

\section{Three-dimensional electrode reconstructions}

Electrode microstructures of two typical cells, named Cell-A and Cell-B thereafter, have been characterized by synchrotron X-ray holotomography. The $\mathrm{O}_{2}$ electrodes for Cell-A and Cell-B are made of Lanthanum doped Strontium Cobaltite (LSC) and Lanthanum doped Strontium Cobaltite Ferrite (LSCF), respectively. The $\mathrm{H}_{2}$ electrodes of both studied cells are composed of a cermet made of Nickel and Yttria Stabilized Zirconia (Ni-YSZ). Besides, the $\mathrm{H}_{2}$ electrode of Cell-B is composed of a thick current collector $(500 \mu \mathrm{m})$ associated to a thin functional layer $(10 \mu \mathrm{m})$. The tomographic experiments have been performed on the Nano-Imaging beamline ID16A-NI at the European Synchrotron Radiation Facility (ESRF). The data acquisition and post-processing have been specifically adapted by adding random displacements during the sample rotation in order to suppress ring-shaped artifacts in the final reconstructions (11). With such an improved method, the $\mathrm{H}_{2}$ and $\mathrm{O}_{2}$ electrodes of the studied cells have been successfully reconstructed with volumes of $\approx 51 \times 25^{2} \times \pi \mu \mathrm{m}^{3}$ and a spatial resolution of $\approx 50 \mathrm{~nm}$ (12). These characteristics of the 3D images allow the accurate description of the geometrical details of the microstructure as well as the morphological heterogeneities at a larger scale. The 3D rendering volumes after reconstruction and segmentation are displayed in Fig. 1 and 2 for the active functional layers of cell-A and Cell-B, respectively. The volume for the current collector of cell-B is shown in Fig. 2c highlighting a bimodal pore size distribution. Isolating the macro-pores from micro-porosities has allowed showing that the disconnected macropores are homogeneously distributed and have ellipsoid-like morphologies with varying degrees of flattening and tilt (9).

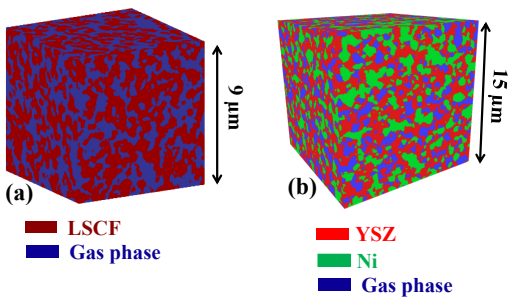

Figure 1. 3D visualization of the reconstructed volumes for the Cell-A with the $\mathrm{O}_{2}$ electrode (a) and the $\mathrm{H}_{2}$ electrode (b). 

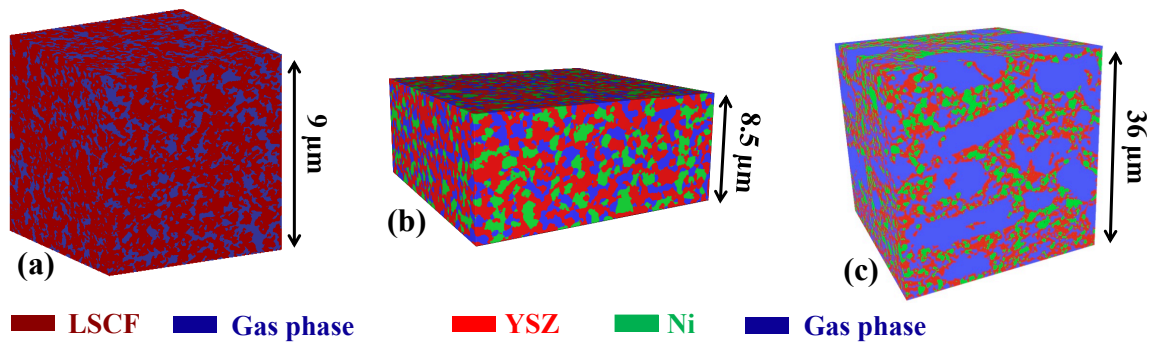

Figure 2. 3D visualization of the reconstructed volumes for the Cell-B with the $\mathrm{O}_{2}$ electrode (a), the $\mathrm{H}_{2}$ electrode (b) and the thick current collector used as mechanical support (c).

The Representative Volume Element (RVE) has been evaluated for each electrode by using the volume expansion method described by Yan et al. (13). Fig. 3 illustrates the results of this approach applied for the Ni phase of Cell-A. The RVE is reached when the standard deviation for each investigated parameter becomes negligible. By using this method, it has been found that the RVE for the two $\mathrm{O}_{2}$ electrodes is equal to $\approx 9 \times 9 \times 9 \mu \mathrm{m}^{3}$ while the one for the $\mathrm{H}_{2}$ electrode of Cell-A is evaluated to $\approx 15 \times 15 \times 15 \mu \mathrm{m}^{3}$. A large cubic volume of $36 \times 36 \times 36 \mu \mathrm{m}^{3}$ is needed for the current collector (Cell-B) in order to be representative of its coarse microstructure. Since the $\mathrm{H}_{2}$ electrode active layer of Cell-B has a thickness limited to $10 \mu \mathrm{m}$ (Fig. 1), it has been shown that the computation on 16 independent Stochastic Volume Elements of $\approx 8.5 \times 8.5 \times 8.5 \mu \mathrm{m}^{3}$ are requested to have good statistics on the investigated properties (i.e. the standard deviation becomes negligible). Based on this preliminary study, the most valuable morphological parameters have been computed on the $3 \mathrm{D}$ volumes to characterize the microstructures (14): (i) connectivity $\delta$, (ii) phase volume fraction $\varepsilon$, (iii) specific surface area $S_{p}$, (iv) constrictivity $\beta$, (v) geometrical tortuosity $\tau^{g e o}$ and (vi) M-factor defined as the ratio the effective to the bulk conductivities for each phase (cf. Table I and Table II).
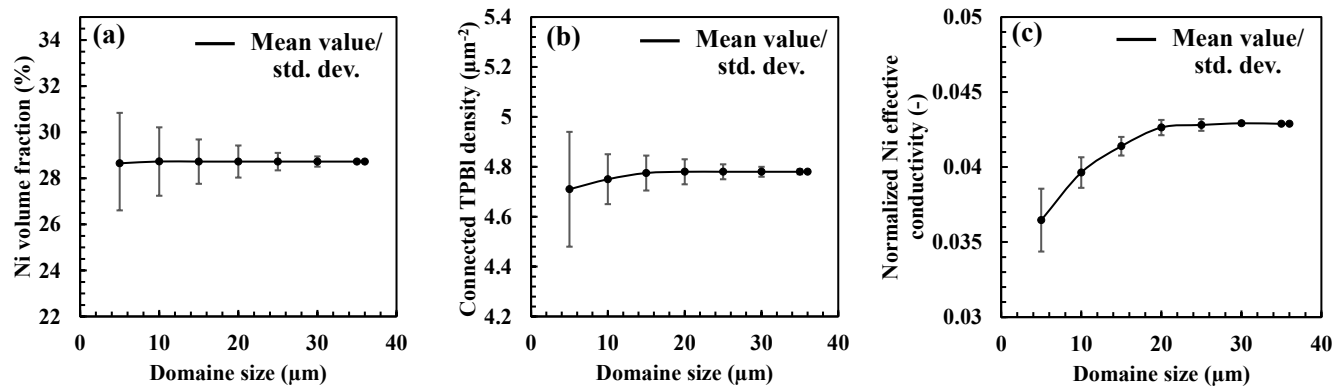

Figure 3. Estimation of the RVE size for the $\mathrm{H}_{2}$ electrode of Cell-A (Ni-YSZ) with respect to the Ni volume fraction (a), the connected TPBl density (b), and the normalized Ni effective conductivity (M-factor) (c).

\section{Generation and validation of synthetic microstructures}

Plurigaussian random field method

Model description. The truncated Gaussian random field model has been employed to generate the electrode microstructures of cell-A and cell-B (8). For a two-phase electrode (i.e. for the porous LSC or LSCF), a direct application of the classical method can be used 
$(7,15)$. As illustrated in Fig. 4, it consists in the generation of a Gaussian random noise $U(z)$. This 'white noise' is then correlated with a weight function $\omega(h)$ that must contain the statistical information on the medium to mimic. This operation aims at introducing the requested spatial correlation in the random field $G_{X}(z)$ as follows:

$$
G_{X}(z)=U(z) * \omega(h) \text { with } \rho_{X}(h)=\operatorname{cov}\left(G_{X}(z), G_{X}(z+h)\right)=(\omega * \omega)(h)
$$

Where $X$ denotes one of the electrode phases (e.g. $X=\operatorname{LSCF}$ or LSC) whereas $\rho_{X}(h)$ is a correlation function 'fitted' on the covariance function $C_{X}(h)$ of the real microstructure (8):

$$
\mathrm{C}_{\mathrm{X}}(\mathrm{h})-\varepsilon_{\mathrm{X}}=\frac{1}{2 \pi} \int_{1}^{\rho_{\mathrm{X}}(\mathrm{h})} \frac{1}{\sqrt{1-\mathrm{r}^{2}}} \exp \left\{\frac{-\lambda_{\mathrm{X}}^{2}}{1+\mathrm{r}}\right\} \mathrm{dr}
$$

Where $\varepsilon_{X}$ denotes the targeted phase volume fraction. To obtain the final microstructure composed of $X$ and its complementary $\bar{X}$ (Fig. 4), the correlated random field is truncated with a threshold $\lambda_{X}$ such as $X=\left\{z, G_{X(z)} \geq \lambda_{X}\right\}$. This threshold is given by the partitioning of the normal distribution described by its probability density function $p(x)$ :

$$
\varepsilon_{X}=\int_{\lambda_{X}}^{\infty} p(x) d x=1-\frac{1}{\sqrt{2 \pi}} \int_{-\infty}^{\lambda_{X}} \exp \left\{\frac{-x^{2}}{2}\right\} d x
$$

(a) Uncorrelated Gaussian random

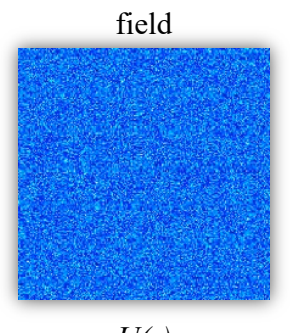

$U(z)$ (b) Correlated Gaussian random field

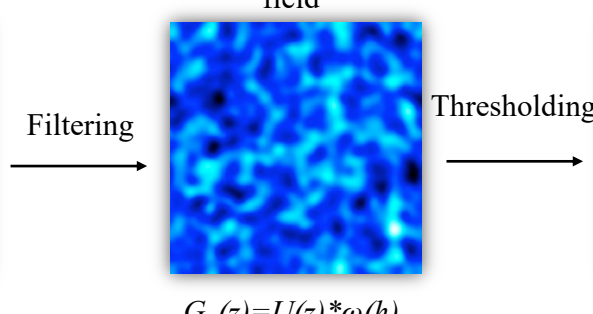

$G_{X}(z)=U(z) * \omega(h)$ (c) Final microstructure

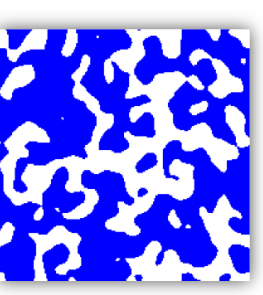

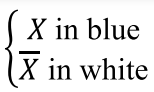

Figure 4. 2D Illustration of the random field model methodology for a two-phase material (a) uncorrelated Gaussian field, also called 'white noise', (b) correlated Gaussian random field (c) the binary image, representing the final microstructure.

The method has been extended to simulate the three-phase electrodes (i.e. for the porous Ni-YSZ). In this case, two random fields $G_{X}(z)$ and $G_{Y}(z)$ must be considered. They are related to the sets $X$ and $Y$ representing two of the three phases for the porous composite electrode (e.g. $\mathrm{X}=\mathrm{Ni}$ and $\mathrm{Y}=\mathrm{YSZ}$ ). The main structure and sequence of the procedure is summarized below:

The first step of the process consists in the generation of the two independent fields with the previous method. They are then combined to form a bigaussian random field $G_{X Y}(z)=$ $\left\{G_{X}(z) ; G_{Y}(z)\right\}$ that follows a normal bivariate distribution. The thresholding of this bigaussian field provides the synthetic microstructure:

$$
X=\left\{z ; G_{X Y}(z) \in D_{X}\right\} ; Y=\left\{z ; G_{X Y}(z) \in D_{Y}\right\} \text { and } Z=\overline{X \cup Y}
$$

As shown in Fig. 5, the identification of the domains $D_{X}$ and $D_{Y}$ results from the partitioning of the probability density function $p(x, y)$ for the bivariate normal distribution. As detailed in (8), this step is carried out to respect the targeted phase volume fractions with an additional constrain on the interfacial specific surface areas. 

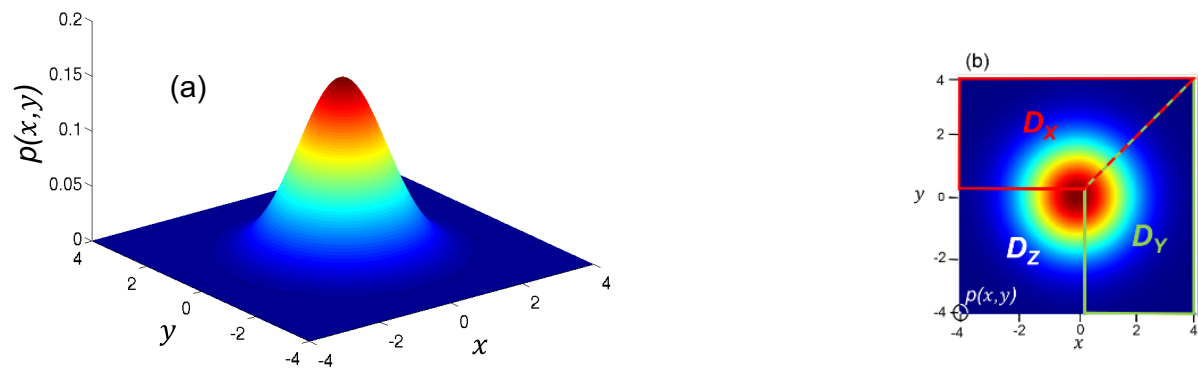

Figure 5. Distribution and definition of the thresholds for a three-phase electrode (e.g. porous Ni-YSZ): the Gaussian field follows a normal bivariate distribution with probability density function $p(x, y)$ (a) segmented with a domain partitioning shown in (b).

Model validation. The 3D rendering volumes of the Random Field (RF) synthetic microstructures are displayed in Fig. 6 for Cell-A and Cell-B. They can be compared to real reconstructions given in Fig. 1 and 2. As a first approach, the visual inspection of the $3 \mathrm{D}$ volumes for both cells reveals that the virtual microstructures seem to mimic quite perfectly the real ones.

(a) Electrodes of Cell-A

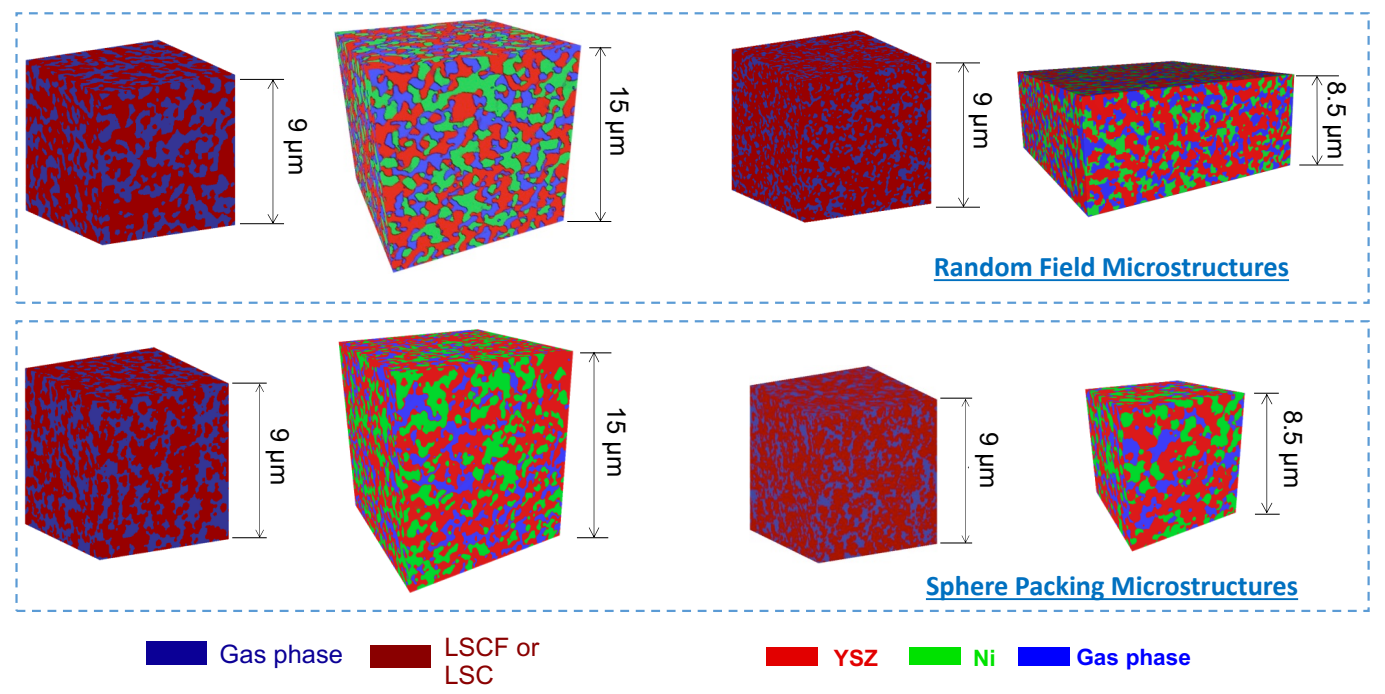

Figure 6. Synthetic microstructures simulated with the Random Field (RF) method and the Sphere Packing (SP) algorithm for the electrodes of Cell-A (a) and Cell-B (b).

To go further in the model validation, the electrode microstructural parameters for the synthetic electrodes have been determined in the same conditions than the data computed with the tomographic reconstructions (i.e. for the same voxel and RVE sizes or number of realizations considering the SVE for the $\mathrm{H}_{2}$ electrode of Cell-B). As an illustration for this analysis, the microstructural properties for the synthetic Ni-YSZ electrode of Cell-A and Cell-B are compared to the real values in Table I and II.

As a general comment for all the investigated electrodes of Cell-A and Cell-B, it has been found that the model is able to accurately retrieve the density of TPBl and the specific surface areas. Indeed, for these two microstructural properties, the mismatch between the 
synthetic material and the real reconstruction does not exceed $+/-5 \%$ whatever the tested electrode. The highest discrepancy has been found on the M-factor and the constrictivity parameter. For the latter, the uncertainty of the model prediction can reach $22 \%$ for the very high constrictive phases (cf. Table I for example). Nevertheless, the model can be considered validated despite this limitation on the transport properties.

TABLE I. Microstructural properties for the $\mathrm{H}_{2}$ electrodes of Cell-A computed on the tomographic reconstruction and the synthetic volumes simulated with the Random Field (RF) and Sphere Packing (SP) methods.

\begin{tabular}{|c|c|c|c|c|c|c|c|c|c|c|c|c|c|c|}
\hline \multicolumn{15}{|c|}{$\mathrm{H}_{2}$ electrode of Cell-A } \\
\hline \multirow[b]{2}{*}{ Properties } & \multicolumn{7}{|c|}{ Gas phase } & \multicolumn{7}{|c|}{ Electronic conducting phase $(\mathrm{Ni})$} \\
\hline & $\begin{array}{l}\mathrm{Sp}_{\mathrm{p}}^{(\mathrm{A})} \\
\mu \mathrm{m}^{-1}\end{array}$ & $\begin{array}{l}\delta^{(B)} \\
(\%)\end{array}$ & $\begin{array}{l}\varepsilon^{(\mathrm{C})} \\
(\%)\end{array}$ & $\begin{array}{l}\mathrm{dp}_{\mathrm{p}}^{(\mathrm{D})} \\
(\mu \mathrm{m})\end{array}$ & $\begin{array}{l}\tau^{\mathrm{geo}} \\
(\mathrm{E}) \\
(-)\end{array}$ & $\begin{array}{l}\beta^{(\mathrm{F})} \\
(-)\end{array}$ & $\begin{array}{c}\text { M-factor } \\
\text { (G) } \\
(-)\end{array}$ & $\begin{array}{c}\mathrm{S}_{\mathrm{p}} \\
\mu \mathrm{m}^{-1}\end{array}$ & $\begin{array}{c}\delta \\
(\%)\end{array}$ & $\begin{array}{c}\varepsilon \\
(\%)\end{array}$ & $\begin{array}{l}\mathrm{dp}^{(*)} \\
(\mu \mathrm{m})\end{array}$ & $\begin{array}{r}\tau^{\mathrm{geo}} \\
(-)\end{array}$ & $\begin{array}{c}\beta \\
(-)\end{array}$ & $\begin{array}{c}\text { M- } \\
\text { factor } \\
(-)\end{array}$ \\
\hline $\begin{array}{c}\text { Real } \\
\mu \text {-structure }\end{array}$ & 2.67 & 94.74 & 28.04 & 0.28 & 1.67 & 0.09 & 0.030 & 2.30 & 97.45 & 27.88 & 0.33 & 1.75 & 0.08 & 0.041 \\
\hline $\begin{array}{l}\text { RF virtual } \\
\mu \text {-structure }\end{array}$ & 2.64 & 99.43 & 28.14 & 0.28 & 1.62 & 0.11 & 0.036 & 2.32 & 99.21 & 27.78 & 0.34 & 1.70 & 0.10 & 0.051 \\
\hline Error & $-1 \%$ & $+4 \%$ & $\sim 0 \%$ & $\sim 0 \%$ & $-3 \%$ & $+22 \%$ & $+21 \%$ & $+1 \%$ & $+2 \%$ & $\sim 0 \%$ & $+3 \%$ & $-3 \%$ & $+25 \%$ & $+25 \%$ \\
\hline $\begin{array}{l}\text { SP virtual } \\
\mu \text {-structure }\end{array}$ & 2.62 & 99.51 & 27.87 & 0.28 & $\begin{array}{c}1.6 \\
2\end{array}$ & 0.10 & 0.035 & 2.25 & 99.34 & 28.12 & 0.33 & 1.65 & 0.09 & 0.049 \\
\hline \multirow[t]{2}{*}{ Error } & $-2 \%$ & $+4 \%$ & $\sim 0 \%$ & $\sim 0 \%$ & $-3 \%$ & $+16 \%$ & $+17 \%$ & $-2 \%$ & $+2 \%$ & $\sim 0 \%$ & $\sim 0 \%$ & $-6 \%$ & $+18 \%$ & $+21 \%$ \\
\hline & \multicolumn{7}{|c|}{ Ionic conducting phase (YSZ) } & \multicolumn{7}{|c|}{ Density of TPBI (Ni/YSZ/gas contact lengths) } \\
\hline Properties & $\mathrm{Sp}_{\mathrm{p}}^{\mu \mathrm{m}^{-}}$ & $\begin{array}{l}\delta \\
(\%)\end{array}$ & $\begin{array}{c}\varepsilon \\
(\%)\end{array}$ & $\begin{array}{l}\mathrm{dp}^{\left({ }^{(*)}\right.} \\
(\mu \mathrm{m})\end{array}$ & $\begin{array}{r}\tau^{\text {geo }} \\
(-)\end{array}$ & $\beta$ & $\begin{array}{c}\text { M-factor } \\
(-)\end{array}$ & \multicolumn{7}{|c|}{$\begin{array}{c}\mathrm{LtPB}(\mathrm{H}) \\
\left(\mu \mathrm{m}^{-2}\right)\end{array}$} \\
\hline $\begin{array}{c}\text { Real } \\
\mu \text {-structure }\end{array}$ & 3.68 & 99.78 & 44.08 & 0.28 & $\begin{array}{c}1.4 \\
3\end{array}$ & 0.13 & 0.189 & \multicolumn{7}{|c|}{4.78} \\
\hline $\begin{array}{l}\text { RF virtual } \\
\mu \text {-structure }\end{array}$ & 3.65 & 99.94 & 44.08 & 0.29 & $\begin{array}{c}1.4 \\
3 \\
\end{array}$ & 0.13 & 0.190 & \multicolumn{7}{|c|}{4.73} \\
\hline Error & $-1 \%$ & $\sim 0 \%$ & $\sim 0 \%$ & $+3 \%$ & $\begin{array}{l}\sim 0 \\
\%\end{array}$ & $\sim 0 \%$ & $\sim 0 \%$ & \multicolumn{7}{|c|}{$-1 \%$} \\
\hline $\begin{array}{l}\text { SP virtual } \\
\mu \text {-structure }\end{array}$ & 3.83 & 99.99 & 44.01 & 0.28 & $\begin{array}{c}1.4 \\
2\end{array}$ & 0.12 & 0.193 & \multicolumn{7}{|c|}{4.97} \\
\hline Error & $+4 \%$ & $\sim 0 \%$ & $\sim 0 \%$ & $\sim 0 \%$ & $-1 \%$ & $-3 \%$ & $+2 \%$ & \multicolumn{7}{|c|}{$+4 \%$} \\
\hline
\end{tabular}

(A) specific surface area, (B) connectivity, (C) volume fraction, (D) mean diameter taken from the PSD, (E) geometrical tortuosity, (F) constrictivity, $(\mathrm{G})$ ratio of effective to bulk conductivities, $(\mathrm{H})$ density of 'active' TPBl computed on the connected phases.

TABLE II. Microstructural properties for the $\mathrm{H}_{2}$ electrodes of Cell-B computed on the tomographic reconstruction and the synthetic volumes simulated with the Random Field (RF) and Sphere Packing (SP) methods.

\begin{tabular}{|c|c|c|c|c|c|c|c|c|c|c|c|c|c|c|}
\hline \multicolumn{15}{|c|}{$\mathrm{H}_{2}$ electrode of Cell-B } \\
\hline \multirow[b]{2}{*}{ Properties } & \multicolumn{7}{|c|}{ Gas phase } & \multicolumn{7}{|c|}{ Electronic conducting phase $(\mathbf{N i})$} \\
\hline & $\begin{array}{l}\mathrm{Sp}_{\mathrm{p}}^{(\mathrm{A})} \\
\mu \mathrm{m}^{-1}\end{array}$ & $\begin{array}{l}\delta^{(\mathrm{B})} \\
(\%)\end{array}$ & $\begin{array}{l}\varepsilon^{(\mathrm{C})} \\
(\%)\end{array}$ & $\begin{array}{l}\mathrm{dp}_{\mathrm{p}}^{(\mathrm{D})} \\
(\mu \mathrm{m})\end{array}$ & $\begin{array}{l}\tau^{\mathrm{geo}} \\
(\mathrm{E}) \\
(-)\end{array}$ & $\begin{array}{c}\beta^{(\mathrm{F})} \\
(-)\end{array}$ & $\begin{array}{c}\text { M-factor } \\
\text { (G) } \\
(-)\end{array}$ & $\underset{\mu \mathrm{m}^{-1}}{\mathrm{~S}}$ & $\begin{array}{c}\delta \\
(\%)\end{array}$ & $\begin{array}{c}\varepsilon \\
(\%)\end{array}$ & $\begin{array}{l}\mathrm{dp}^{(*)} \\
(\mu \mathrm{m})\end{array}$ & $\begin{array}{r}\tau^{\mathrm{geo}} \\
(-)\end{array}$ & $\begin{array}{l}\beta \\
(-)\end{array}$ & $\begin{array}{c}\text { M- } \\
\text { factor } \\
(-)\end{array}$ \\
\hline $\begin{array}{c}\text { Real } \\
\mu \text {-structure }\end{array}$ & 2.94 & 94.23 & 26.55 & 0.24 & $\begin{array}{c}1.7 \\
4\end{array}$ & 0.39 & 0.021 & 2.46 & 92.81 & 24.13 & 0.28 & 1.81 & 0.34 & 0.018 \\
\hline $\begin{array}{l}\text { RF virtual } \\
\mu \text {-structure }\end{array}$ & 2.87 & 98.65 & 26.80 & 0.25 & $\begin{array}{c}1.6 \\
6\end{array}$ & 0.45 & 0.026 & 2.41 & 97.75 & 24.82 & 0.28 & 1.74 & 0.41 & 0.021 \\
\hline Error & $-2 \%$ & $+4 \%$ & $+1 \%$ & $+4 \%$ & $-4 \%$ & $+15 \%$ & $+24 \%$ & $-2 \%$ & $+5 \%$ & $+2 \%$ & $\sim 0 \%$ & $-4 \%$ & $+21 \%$ & $+17 \%$ \\
\hline $\begin{array}{l}\text { SP virtual } \\
\mu \text {-structure }\end{array}$ & 3.05 & 99.51 & 26.16 & 0.24 & $\begin{array}{c}1.6 \\
9 \\
\end{array}$ & 0.43 & 0.025 & 2.53 & 98.38 & 24.41 & 0.28 & 1.76 & 0.39 & 0.021 \\
\hline \multirow[t]{2}{*}{ Error } & $+4 \%$ & $+4 \%$ & $\sim 0 \%$ & $\sim 0 \%$ & $-3 \%$ & $+11 \%$ & $+17 \%$ & $+3 \%$ & $+6 \%$ & $+1 \%$ & $+1 \%$ & $-3 \%$ & $+16 \%$ & $+18 \%$ \\
\hline & \multicolumn{7}{|c|}{ Ionic conducting phase (YSZ) } & \multicolumn{7}{|c|}{ Density of TPBI (Ni/YSZ/gas contact lengths) } \\
\hline \multirow{3}{*}{$\begin{array}{c}\text { Properties } \\
\text { Real } \\
\mu \text {-structure } \\
\text { RF virtual } \\
\mu \text {-structure }\end{array}$} & $\mathrm{Sp}_{\mathrm{p}}^{\mu \mathrm{m}^{-}}$ & $\begin{array}{c}\delta \\
(\%)\end{array}$ & $\begin{array}{c}\varepsilon \\
(\%)\end{array}$ & $\begin{array}{l}\mathrm{dp}^{(*)} \\
(\mu \mathrm{m})\end{array}$ & $\begin{array}{r}\tau^{\text {geo }} \\
(-)\end{array}$ & $\begin{array}{c}\beta \\
(-)\end{array}$ & $\begin{array}{l}\text { M-factor } \\
(-)\end{array}$ & \multicolumn{7}{|c|}{$\begin{array}{c}\mathrm{LTPB}(\mathrm{H}) \\
\left(\mu \mathrm{m}^{-2}\right)\end{array}$} \\
\hline & 3.42 & 99.92 & 49.55 & 0.31 & $\begin{array}{c}1.1 \\
4\end{array}$ & 0.44 & 0.243 & \multicolumn{7}{|c|}{6.20} \\
\hline & 3.45 & 99.98 & 48.38 & 0.31 & $\begin{array}{c}1.1 \\
3\end{array}$ & 0.47 & 0.246 & \multicolumn{7}{|c|}{6.07} \\
\hline Error & $+1 \%$ & $\sim 0 \%$ & $-2 \%$ & $\sim 0 \%$ & $-1 \%$ & $+7 \%$ & $+1 \%$ & \multicolumn{7}{|c|}{$-2 \%$} \\
\hline $\begin{array}{c}\text { SP virtual } \\
\mu \text {-structure }\end{array}$ & 3.46 & 99.99 & 49.43 & 0.31 & $\begin{array}{c}1.1 \\
3 \\
\end{array}$ & 0.47 & 0.248 & \multicolumn{7}{|c|}{5.83} \\
\hline Error & $+3 \%$ & $\sim 0 \%$ & $\sim 0 \%$ & $+1 \%$ & $-1 \%$ & $+8 \%$ & $+2 \%$ & \multicolumn{7}{|c|}{$-6 \%$} \\
\hline
\end{tabular}




\section{Sphere packing algorithm}

In complementarity with the non-iterative mathematical model based on the Random Field method, an original particle-based algorithm has also been developed (9). In this case, the packed structures must mimic the characteristics of two-phase and three-phase electrodes commonly fabricated with the sintering of powder materials. Ionic-conducting and electronic-conducting particles are used to emulate the solid phases, while the porosity constitutes the complementary phase of the partially densified medium.

Model description. The process is divided into four steps as depicted in Fig. 7 for a two-phase medium (i.e. LSCF or LSCF electrodes):

(a) Initial sphere allocation: Initial spheres with a Weibull distribution $p_{\text {Weibull }}$ on the particle size are initially distributed on an empty volume $V$ :

$$
p_{\text {Weibull }}(r)=\frac{k}{\lambda}\left(\frac{r}{\lambda}\right)^{k-1} e^{-(r / \lambda)}
$$

Where $r$ is the random variable for the sphere radius, while $k$ and $\lambda$ are the shape and scale parameters of the probability density function, respectively. The positioning of the initial spheres in the domain is crucial to control the pattern of the microstructure and the possibility to have some local aggregation in the final medium. For this purpose, a specific procedure has been implemented by dividing the domain $V$ into $n_{\text {seed }}^{3}$ cubic sub-volumes $U_{i \in \llbracket 1, n_{\text {seed }}^{3} \rrbracket}$. In each sub-volume, an initial sphere is randomly placed as shown in Fig. 7a for a $2 \mathrm{D}$ slice cross-section. The number of initial spheres or seeds, $n_{\text {seed }}$, is then a model parameter that needs to be tuned depending on the microstructure to emulate.

(b) Volume filling - In order to fill the volume and reach the targeted pore volume fraction, new spheres (following the same Weibull distribution as the initial ones) are added in the domain (Fig. 7b). In this iterative process, each new sphere is dropped in the building microstructure to be in contact with an existing one, already positioned in the volume. This procedure ensures a good solid phase connectivity as it is observed in real microstructures (cf. Table I and II). During the process, a controlled overlap is allowed between the adjacent particles (Fig. 8). In practice, the distance between two overlapping spheres $S_{i}$ and $S_{j}$ with respective radii $r_{i}$ and $r_{j}$ is defined as follows:

$$
d_{i j}=\left(r_{i}+r_{j} / 2\right)(1+\text { rand })
$$

where rand denotes a uniformly distributed random variable in the interval $[0,1]$. With this method, the overlap extent is equally distributed between two bounded positions (ranging from $d_{i j}=\left(r_{i}+r_{j}\right) / 2$ to the punctual contact). Besides, the direction of each new sphere with respects to the old one needs to be totally random in order to account for the isotropy of the sintered electrode. Therefore, the azimuth and elevation angles, $\Phi$ and $\theta$, have been expressed in the spherical coordinates system as follows (Fig. 8):

$$
\Phi=2 \pi \times \operatorname{rand}_{1} \text { and } \theta=\arcsin \left(\operatorname{rand}_{2}\right)
$$

Where $\mathrm{rand}_{1}$ and $\mathrm{rand}_{2}$ are two uniformly distributed random variables in the interval $[0,1]$. Finally, the number of interconnections is constrained in the model. For this purpose, the coordination number is computed for each sphere, and a maximum value $\mathrm{n}_{\text {coord }}$ is set to avoid non-realistic local heterogeneities.

(c) Creation of neck curvature - The previous step of the algorithm leads to the formation of neck between the particles due to the sintering. Nevertheless, the mass transfer resulting from the diffusion of solid mater to the particle intersections also yields the creation of 
neck curvature (Fig. 7c). In our case, this radius is created by using a morphological opening defined as the dilation of the erosion applied on the microstructure (15). For this operation, a spherical structuring element is used with a diameter of one-sixth to one-fifth of the mean particle size (9).

(d) Removing edge effect artifact - As the spheres have less probability to occupy the regions close to the external faces of the simulated domain, slices with a thickness of around the mean diameter of the solid phase have been removed from each side of the cubic volume (Fig. 7d).

The particle-based model has also been extended to simulate the Ni-YSZ porous composite electrodes. In this case, two sphere populations related to the two solid phases are considered (each one having a distinct Weibull distribution). At each step of the process, the attribution of the ionic or electronic nature of the new particle is carried out with a constraint added to fulfill the targeted electrode composition. Besides, in order to maintain a high phase connectivity, each new sphere is positioned in contact with an existing particle of the same nature.

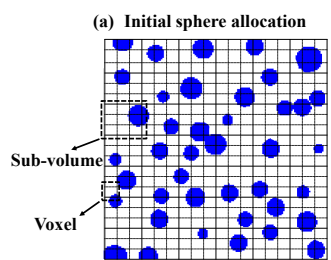

(c) Creation of neck curvature

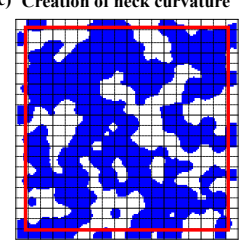

(d) Edge effect correction

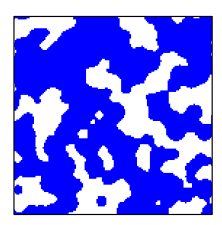

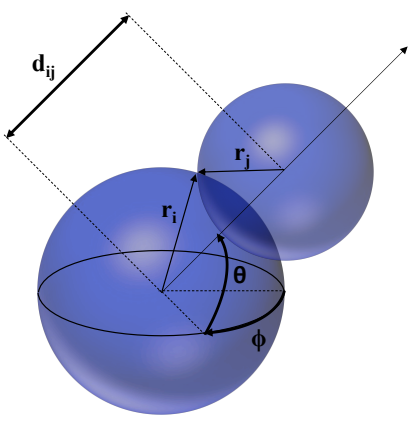

Figure 8. Schematic representation of the contact geometry between two particles.

Model Validation. The 3D rendering volumes of the Sphere Packing (SP) microstructures are shown in Fig. 6 for Cell-A and Cell-B. As a preliminary remark, the synthetic microstructures seem to reproduce accurately the morphology of the real electrodes displayed in Fig. 1 and Fig. 2. More precisely, as shown in Table I and II for the Ni-YSZ electrodes, the metric properties are well captured by the SP method with a maximum relative error of $+/-4 \%$. This margin of uncertainties on the SP model predictions is lying in the same range as the one calculated with the RF method. Interestingly, as found for the RF microstructures, the SP model also fails to accurately reproduce the constrictivity parameter and the M-Factor when the phase volume fraction is approaching the percolation threshold. In this particular case, the relative error can reach $21 \%$ (cf. Table I and II). Further investigations should be done to improve this 'limitation' for the phases close to the percolation threshold. Nevertheless, considering the negligible overall mismatches, the SP microstructures can be considered representative of the real SOCs electrodes.

Microstructure of the Ni-YSZ thick current collector. The SP model has been adapted to take into account the bimodal pore size distribution for the Ni-YSZ substrate of Cell-B. 
By using the previous algorithm, a first synthetic microstructure is generated for the percolated micro-porosity and solid phases (resulting from the sintering of powders). The second step of the process is devoted to produce a volume with the disconnected macropores (coming from the use of pore formers). In this case, a specific algorithm has been developed to describe the morphology and the orientation of the macro-pores (thanks to parameterized ellipsoid particles with a distribution on size, degree of flattening and orientation) (9). Finally, the two volumes are merged to simulate the microstructure with the bi-modal pore size distribution.

The visual comparison of the $2 \mathrm{D}$ slice cuts of the real and synthetic microstructures is shown in Fig. 9. It can be seen that the two structures are geometrically similar. To confirm this observation, the microstructural properties have been computed on the real tomographic reconstruction and the numerical microstructure. As shown in Table III, a good agreement is found between the two sets of data proving the reliability of the method. For example, the addition of macro-pores yields a rather low geometrical tortuosity and constrictivity for the gas phase (Table III). This specificity is well retrieved by the model.
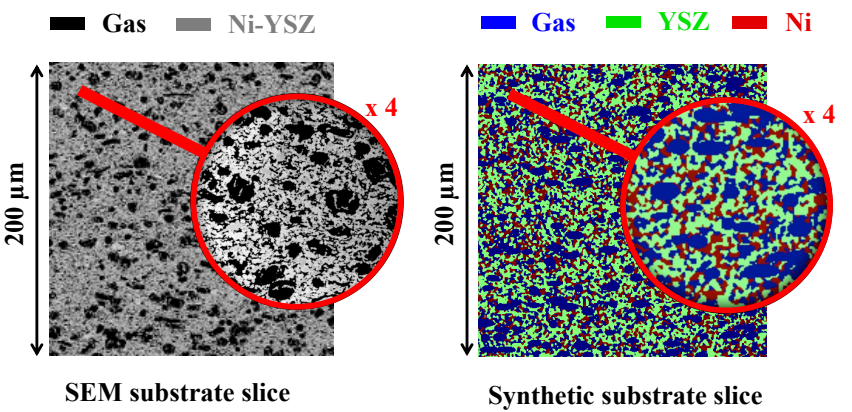

Figure 9. Comparison of the 2D slice cuts of the real and synthetic microstructures.

TABLE III. Microstructural properties for the Ni-YSZ substrate of Cell-B computed on the real reconstruction and SP synthetic volume. The porosity is divided into micro-porosity and macro-porosity

\begin{tabular}{|c|c|c|c|c|c|c|c|c|c|}
\hline & \multicolumn{8}{|c|}{ Ni-YSZ substrate (current collector) of Cell-B } & \\
\hline $\begin{array}{c}\text { Properties } \\
\text { Units } \\
\end{array}$ & $\begin{array}{c}S_{p} \\
\mu m^{-1}\end{array}$ & $\begin{array}{l}\delta \\
\%\end{array}$ & $\begin{array}{c}\varepsilon \\
\%\end{array}$ & $\begin{array}{l}d_{p} \\
\mu \mathrm{m}\end{array}$ & $\begin{array}{c}\tau^{\mathrm{geo}} \\
-\end{array}$ & $\begin{array}{l}\beta \\
-\end{array}$ & $\begin{array}{c}\text { M-factor } \\
-\end{array}$ & $\begin{array}{c}\text { TPBI density } \\
\mu \mathrm{m}^{-2}\end{array}$ & \\
\hline Micro-porosity & 1.92 & & 31.25 & 0.61 & & & & & \\
\hline Macro-porosity & 0.28 & 99.94 & 14.21 & 2.48 & 1.62 & 0.20 & 0.131 & & Real \\
\hline YSZ phase & 1.79 & 99.22 & 34.85 & 0.56 & 1.78 & 0.43 & 0.100 & 3.19 & $\mu$-structure \\
\hline Ni phase & 1.25 & 96.71 & 19.69 & 0.42 & 2.20 & 0.35 & 0.011 & & \\
\hline Micro-porosity & 1.86 & 909 & 31.51 & 0.63 & 157 & ר? & 0140 & & \\
\hline Macro-porosity & 0.26 & 99.91 & 13.46 & 2.42 & 1.01 & 0.22 & 0.140 & 308 & Synthetic \\
\hline YSZ phase & 1.81 & 99.43 & 34.98 & 0.56 & 1.73 & 0.43 & 0.110 & 3.08 & $\mu$-structure \\
\hline Ni phase & 1.28 & 98.46 & 20.05 & 0.43 & 2.08 & 0.36 & 0.013 & & \\
\hline
\end{tabular}

\section{Microstructural correlations for porous composite electrode}

\section{$\underline{\text { Semi-analytical relations }}$}

In order to optimize the SOCs performances and durability, it can be worthwhile expressing the microstructural properties controlling the electrochemical response as a function of the geometrical attributes describing the porous electrode. These "basic" microstructural parameters of the microstructure can be defined by (i) the porosity, $\varepsilon_{p}$, (ii) the relative phase 
volume fraction of solid phases, $\alpha=\theta_{Y S Z} / \theta_{N i}$, and (iii) the parameters describing the shape and the distribution of the particles (for the ionic and electronic conductors). In that objective, Gokhale et al. (17) have used the concept of 'extended' microstructure (18) to propose the following correlation for the density of TPBl:

$$
L_{T P B}=\frac{\pi}{4} \frac{\alpha}{(1+\alpha)^{2}} \varepsilon_{p}\left(\ln \varepsilon_{p}\right)^{2} \beta_{Y S Z} \beta_{N i} \frac{1}{\left\langle D_{Y S Z}\right\rangle\left\langle D_{N i}\right\rangle} \frac{\left(1+C V_{Y S Z}{ }^{2}\right)}{\left(1+3 C V_{Y S Z}{ }^{2}+\gamma_{Y S Z} C V_{Y S Z}{ }^{3}\right)} \frac{\left(1+C V_{N i}{ }^{2}\right)}{\left(1+3 C V_{N i}{ }^{2}+\gamma_{N i} C V_{N i}{ }^{3}\right)}
$$

Where the mean particle size $\left\langle D_{i}\right\rangle$, the Coefficient of Variation $C V_{i}$ and the skewness $\gamma_{i}$ are the three parameter describing the particle size distribution for the ionic (YSZ) and electronic (Ni) phases. By following the same approach, the correlations for interfacial specific surface areas have been derived for the contact between the Ni and the pores, eq. [9], the YSZ and the pores, eq. [10] and for the two solid phases, eq. [11]. All the details for the demonstrations are given in (10):

$$
\begin{gathered}
S_{N i / p}=\frac{-1}{1+\alpha} \varepsilon_{p} \ln \left[\varepsilon_{p}\right] \beta_{N i} \frac{1}{\left\langle D_{N i}\right\rangle} \frac{\left[1+C V_{N i}{ }^{2}\right]}{\left[1+3 C{V_{N i}}^{2}+\gamma_{N i} C V_{N i}{ }^{3}\right]} \\
S_{Y S Z / p}=\frac{-\alpha}{1+\alpha} \varepsilon_{p} \ln \left[\varepsilon_{p}\right] \beta_{Y S Z} \frac{1}{\left\langle D_{Y S Z}\right\rangle} \frac{\left[1+C V_{Y S Z}{ }^{2}\right]}{\left[1+3 C V_{Y S Z}{ }^{2}+\gamma_{Y S Z} C V_{Y S Z}{ }^{3}\right]} \\
S_{N i / Y S Z}=\frac{\pi}{8} \frac{\alpha}{(1+\alpha)^{2}} \varepsilon_{p}\left(\ln \varepsilon_{p}\right)^{2} \frac{\beta_{Y S Z} \beta_{N i} a}{\sqrt{\left.\max \left\{\left\langle D_{N i}\right\rangle,\left\langle D_{Y S Z}\right\rangle\right\} \times\left(D_{Y S Z}\right\rangle+\left\langle D_{N i}\right\rangle\right)}} \\
\times \frac{\left(1+C{V_{Y S Z}}^{2}\right)}{\left(1+3 C{V_{Y S Z}}^{2}+\gamma_{Y S Z} C V_{Y S Z}{ }^{3}\right)} \frac{\left(1+C V_{N i}{ }^{2}\right)}{\left(1+3 C{V_{N i}}^{2}+\gamma_{N i} C V_{N i}{ }^{3}\right)}
\end{gathered}
$$

Where the parameters $\beta_{e l}, \beta_{i o}$, are related to the geometry of the particle collection considered for the analytical demonstration, and $a$ is a parameter associated to their interaction. Nevertheless, knowing that the solid phases of the real SOCs electrode exhibit a continuous shape for which it is not possible to identify a characteristic particle geometry (Fig. 1 and 2), the three parameters have been considered as scaling factors that must be fitted on the 3D microstructures. Therefore, the relationships for $\mathrm{L}_{\mathrm{TPB}}$ and $\mathrm{S}_{\mathrm{i} / \mathrm{j}}$ given in eqs [8]-[11] can be seen as semi-analytical correlations.

\section{Calibration and validation}

In order to determine the three fitting parameters and to validate the correlations, a large database of synthetic microstructures has been generated with the RF and SP models. In this sensitivity analysis, the Ni-YSZ microstructure of Cell-A has been taken as the reference. The dataset of synthetic volumes has been produced by changing the porosity, the electrode composition and the mean phase diameters (with volume fractions higher than $\approx 18 \%$ to keep a good percolation for all the phases). Afterwards, all the properties needed for the correlations have been measured on the 3D microstructures. Once the three scaling parameters fitted, the density of TPBl and all the interfacial specific surface areas have been computed on the synthetic volumes. The results are plotted in Fig. 10 as a function of the predictions given by the microstructural correlations. It can be seen that all the points are aligned with a slope equal to 1 meaning that the two sets of data are identical (either for the RF or the SP models). In other words, the semi-analytical correlations are found to capture all the evolutions in terms of porosity, electrode composition and mean phase diameters. Moreover, it is worth noting that the values for scaling factors identified by fitting the RF and SP microstructures are very close $\left(\beta_{Y S Z}^{R F} / \beta_{Y S Z}^{S P}=0.97, \beta_{N i}^{R F} / \beta_{N i}^{S P}=1.01\right.$ and $\left.a^{R F} / a^{S P}=1.02\right)$. It means that the two predictions remain fully coherent when considering the two approximations given by the RF and SP models. Finally, the correlations have been 
used to calculate the properties of the Ni-YSZ electrode of Cell-B. It has been found that the equations are able to predict the electrode properties with a margin of error that does not exceed 7\% (10). As a consequence, it can be claimed that the correlations are able to accurately predict the density of TPBl and the interfacial surface areas for 'typical' SOC electrodes (manufactured by the classical manufacturing routes for ceramics).
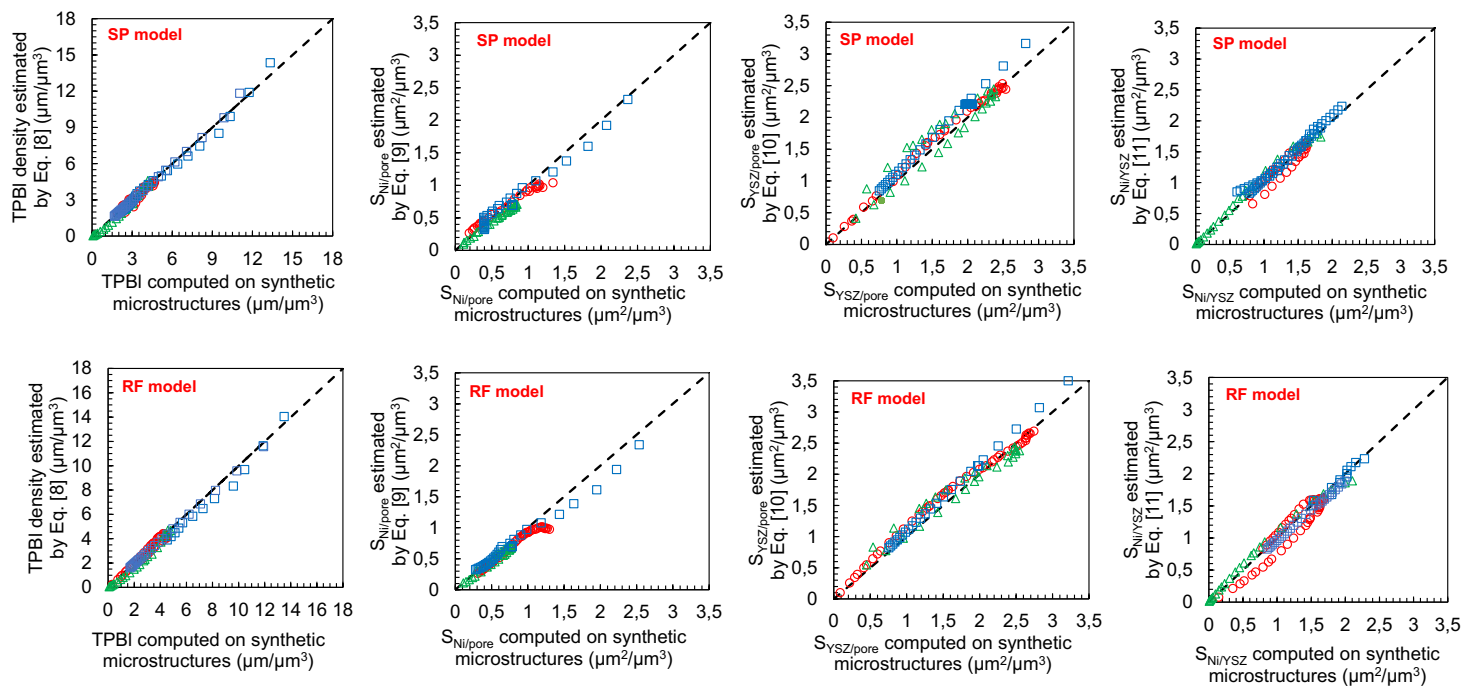

Figure 10. Density of TPB1, interfacial specific surface areas for Ni/pores, YSZ/pores and YSZ/Ni computed on the SP and RF microstructures plotted as a function of the values calculated with the correlations [8]-[11].

Modeling the TPB1 loss due to Ni agglomeration

Reconstructions by X-ray holotomography have been acquired for the Ni-YSZ electrode of Cell-A after different long-term operations at $850^{\circ} \mathrm{C}$ (19). All the microstructural properties have been computed on the reconstructed volumes before and after ageing in order to detect and quantify any morphological evolution in the electrode. As expected, the data analyses have revealed a substantial Ni particle coarsening that can be described by an Ostwald ripening power-law model:

$$
\left[\left\langle D_{N i}(t)\right\rangle^{n}-\left\langle D_{N i}(t=0)\right\rangle^{n}\right]=k_{\text {pow }} \times t
$$

Where $t$ is the time, $k_{\text {pow }}$ the rate constant and the exponent $n$ taken to 8 to fit accurately the experimental data (19). As depicted in Fig. 11, the characterizations have revealed that the Ni agglomeration induces a significant loss to TPBl, whereas the volume fractions and the mean phase diameters for the complementary phases remain quite unaffected by the ageing. To compute the TPBl decrease, Eq. [9] and [12] can be combined to form a physically-based model for the Ni agglomeration. As shown in Fig. 11, it is found that the prognosis given by the model is in good agreement with TPBl density measured on the 3D reconstructions. 


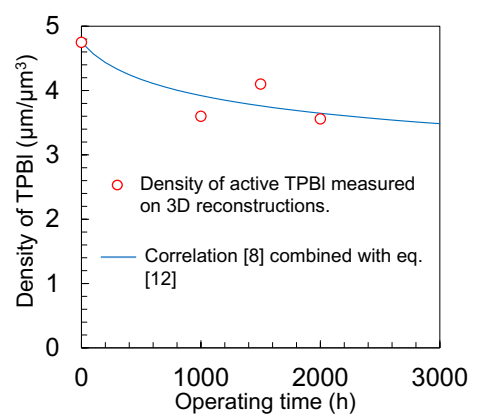

Figure 11. Evolution of the density of TPBl upon operation due to the $\mathrm{Ni}$ agglomeration.

\section{Conclusions}

Two distinct models have been developed to generate synthetic but realistic microstructures of SOCs electrode. The proposed methods are based on two different considerations; the first one is built on an original particle-based algorithm, while the second one is founded on the plurigaussian random field method based on geostatistics. This difference was necessary to obtain two approximations of the same media, and thus to draw conclusions that do not depend on the chosen model. The validation of both models has been carried out with various electrode reconstructions acquired on Ni-YSZ, LSCF and LSC functional layers. The sphere-parking model has also been adapted to the coarse microstructure of typical current collectors exhibiting a bi-modal distribution on the pore size. This second version of the sphere-packing model has been specifically validated with the reconstruction of a typical Ni-YSZ cell substrate. It has been shown that the numerical volumes mimic accurately all the morphological properties for the electrodes active layers as well as the properties of the thick current collector. Nevertheless, both numerical tools fell short from perfectly retrieving the high constrictivities of the phases with low volume fractions, and thus close to the percolation threshold. Microstructural correlations for the density of TPBl and the interfacial specific surface areas have been calibrated by using two datasets of synthetic microstructures generated from the developed models. It has been shown that the correlations are able to capture all the evolutions in terms of porosity, electrode composition and mean phase diameters. Finally, combining the calibrated equation for the density of TPBl with a power-law model describing the particle growth due the Ni coarsening allow to predict the loss of TPB1 upon operation.

\section{Acknowledgements}

The research leading of these results has received funding from the European Horizon 2020 - Research and Innovation Framework program (H2020-JTI-FCH-2015-1 and 2018-1) under grant agreement $\mathrm{n}^{\circ} 735918$ (INSIGHT project), $\mathrm{n}^{\circ} 699892$ (ECO project) and $\mathrm{n}^{\circ} 825027$ (AD ASTRA project). The work has also been partially supported by the French National Agency (ANR) (ECOREVE project) and the Carnot Institute Energies du Futur (DURASOC project). 


\section{References}

1. A.V. Virkar, J. Chen, C.W. Tanner, J.-W. Kim, Solid State Ionics, 131, 189 (2000).

2. K. Chen and S. P. Jiang, J. Electrochem. Soc., 163(11), F3070 (2016).

3. P. R. Shearing, D. J. L. Brett and N. P. Brandon, Int. Mater. Rev., 55(6), 347 (2006).

4. J. Villanova, P. Cloetens, H. Suhonen, J. Laurencin, F. Usseglio-Viretta, E. Lay, G. Delette, P. Bleuet, D. Jauffres, D. Roussel, A.Z. Lichtner, C.L. Martin, J. Mater. Science, 495626 (2014).

5. Y. Nishida and S. Itoh, Electrochimica Acta, 562792 (2011).

6. L.C.R. Schneider, C.L. Martin, Y. Bultel, D. Bouvard, E. Siebert, Electrochimica Acta, 52, 314 (2006).

7. C. Lantuéjoul, Geostatistical Simulation, Model and Algorithms, Springer (2002).

8. H. Moussaoui, J. Laurencin, Y. Gavet, G. Delette, M. Hubert, et al., Comput. Mater. Sci., 143, 262 (2018).

9. H. Moussaoui, Thesis, Univ. Grenoble-Alpes, Grenoble, France (2019).

10. H. Moussaoui, R.K. Sharma, J. Debayle, Y. Gavet, G. Delette, J. Power Sources, 412, 736 (2019).

11. M. Hubert, A. Pacureanu, C. Guilloud, Y. Yang, J.C. da Silva, J. Laurencin, F. Lefebvre-Joud, P. Cloetens, Appl. Phys. Lett., 112, 203704-1 (2018).

12. M. Hubert, J. Laurencin, P. Cloetens, J.C. Da Silva, F. Lefebvre-Joud, P. Bleuet, A. Nakajo, E. Siebert, Solid State Ionics, 294, 90 (2016).

13. Z. Yan, S. Hara, Y. Kim, N. Shikazono, Int. J. Hydrogen Energy, 42, 30166 (2017).

14. J. Laurencin, J. Mougin, Chapt. 6: High-temperature steam electrolysis, In: Hydrogen Production by Electrolysis, Ed. by A. Godula-Jopek, Wiley (2015).

15. M. Armstrong, A. Galli, H. Beucher, G. Le Loc'h, D. Renard, B. Doligez, R. Eschard, F. Geffroy, Plurigaussian Simulations in Geosciences, Springer, 2011

16. J. Serra, Image analysis and mathematical morphology: Theoretical advances, Academic Press, Cornell University (1988).

17. A.M. Gokhale, S. Zhang, M. Liu, J. Power Sources, 194, 303 (2009).

18. M. Fanfoni, M. Tomellini, Il Nuovo Cimento, 20D, 1171 (1998).

19. M. Hubert, J. Laurencin, P. Cloetens, B. Morel, D. Montinaro, F. Lefebvre-Joud, J. Power Sources, 397, 240 (2018). 